\title{
EVALUATION OF PRESCRIBING PATTERN OF FIXED DOSE COMBINATIONS OF ANTIHYPERTENSIVES AND ANTIDIABETIC AGENTS
}

\author{
NIYATI D VYAS ${ }^{1 *}$, ALPA P GOR ${ }^{2}$, JALPA V SUTHAR ${ }^{3}$ \\ ${ }^{1}$ Department of Pharmacy, Ramanbhai Patel College of Pharmacy, Charotar University of Science and Technology Campus-Changa, Gujarat, \\ India. ${ }^{2}$ Department of Pharmacology, Pramukhswami Medical College, Karamsad, Gujarat, India. ${ }^{3}$ Department of Clinical Pharmacy, \\ Ramanbhai Patel College of Pharmacy, Charotar University of Science and Technology Campus-Changa, Gujarat, India. \\ Email: niyativyas.88@gmail.com
}

Received: 06 April 2017, Revised and Accepted: 25 May 2017

\section{ABSTRACT}

Objective: The objective of this research was to evaluate prescribing pattern of fixed dose combinations (FDCs) of antihypertensives and antidiabetic agents among patients of private hospitals.

Methods: An observational study was carried out in the outpatient department of two hospitals. Data of patients being diagnosed with the symptoms of hypertension and diabetes were enrolled which mainly included information related to prescribe FDCs, i.e., antihypertensives and antidiabetics, respectively. Descriptive analysis of collected information was done which involved representation of demographical data, number of comorbidities, number of FDCs prescribed, and type of FDCs consequently.

Results: Combination drug therapy was prescribed in maximum patients, which was enumerated as $93 \%$ among hypertensive patients and about $91 \%$ in diabetics. Average age of patients suffering more from hypertension was $64.5 \pm 18$ years and that in case of diabetes sufferers was $54.5 \pm 18$ years. The most frequent combination prescribed in hypertensive patients was of angiotensin receptor blocker (ARB) and calcium channel blocker (CCB) which were about $53 \%$, and in diabetic patients, it was of biguanides and sulfonylureas about $63 \%$. Comorbidity too was notified, and its estimation was $61 \%$ in hypertensive patients and $72 \%$ in diabetic patients, respectively.

Conclusion: The study here demonstrates that the most often prescribed antihypertensive combination is of ARB and CCB, and subsequently for diabetes, the oral hypoglycemic combination is of biguanides and sulfonylureas. Most of FDCs contained medications of these two classes. Positive results were also observed in levels of blood pressure and glucose within the normal range.

Keywords: Fixed dose combinations, Antihypertensives, Antidiabetics.

(C) 2017 The Authors. Published by Innovare Academic Sciences Pvt Ltd. This is an open access article under the CC BY license (http://creativecommons. org/licenses/by/4. 0/) DOI: http://dx.doi.org/10.22159/ajpcr.2017.v10i9.18966

\section{INTRODUCTION}

Nowadays, hypertension and diabetes are considered to be in the category of most common diseases among individuals. Specificity of patient's prescription depends on individuals age, gender, and presence of comorbid condition if any. Furthermore, the follow-up guidelines, i.e., by the World Health Organization (WHO) and the Joint National Committee (JNC) are necessary as also the follow up guidelines i.e. by World Health Organization and Joint National Committee are necessary. These guidelines are indicative as standard one and patient's glucose and BP levels should be determined in its comparative terms. Dependency of pharmacological treatment is also on age, gender, and body mass index. In most of the cases, more than one drug is required to control BP or glucose level. The categorization of the drugs as to be given as single or in combination is dependent on JNC and other such regulations. In initial treatment terms, single therapy is being employed which later is being followed with a combined therapy on basis of patient's health condition. In case of hypertensive patients, therapy management done by the JNC is as per stages [1]: Stage 1: BP (>140/90 mmhg) first recommended calcium channel blocker (CCB) and if needed add angiotensin-converting enzyme (ACE)/angiotensin receptor blocker (ARB) and second recommended is CCB+thiazide and addition of beta blockers (BBs) is done to it. Stage 2: BP (>160/100 mmhg), started with two drugs which are CCB or thiazide+ACE or ARB and ended with three drugs combined which are $\mathrm{CCB}+$ thiazide+ACE/ARB. For diabetic patients, pharmacological therapy is in terms of insulin usage as a prime preference in diabetes mellitus (DM)-1 patients and oral hypoglycemic agents' usage in DM-2 sufferers. Guidelines of WHO are utilized as prescribing indicators on the basis of which antidiabetic drugs are to be prescribed by Ramachandran et al. [2] and Shahir et al. [3]. Drug management is done as follows [3,4]: If normal glucose level is not achieved by lifestyle modification, then metformin is given as initial treatment drug. If single oral hypoglycemic agent does not seem useful, then the second agent is added along with the first one, and combinative treatment is advised. These fixed dose combinations (FDCs) are defined to be as manufactured medications containing mixture of two or more drugs with the aim of targeting required physiological system at cellular level and providing essential therapeutic outcome by blocking other counter regulatory responses even at their low doses $[5,6]$. Substances/agents used in these FDCs are selected in a manner, where both possess opposite side effects and must act as neutralizing one consequently $[5,6]$. Combination therapy preferred must be in consideration of convenience and tolerability of the patient with least adverse effects. As per the JNC, classification of antihypertensives is done as follows: CCBs, diuretics, ARBs, and ACE inhibitors (ACEI) [5,6]. Similarly, as per the WHO, classification of antidiabetics is done as follows: Biguanides, sulfonylureas, thiazolidinedione, and dipeptidyl peptidase- 4 inhibitors. Advantages of these combined drug therapies are rationalized administration, better acceptance, decreased troublesome in capsule consumption, and reduction in the cost compared to individual medicines $[5,6]$, on other sides, its disadvantages are a reduction in dose versatility and elevation in dose-dependent reactions [5,6]. Evaluation of drug usage can thus be considered as a helping tool in recognizing condition of disease, medication prescribing process, and drug usage process which eventually confers as a rational drug treatment [7]. Hence, the main aim of this study was to narrate prescription pattern among hypertensive and 
diabetic patients in the outpatient department of two hospitals to explain the FDC treatment as a better method of drug management.

\section{METHODS}

\section{Context}

An observational and descriptive study was conducted in the outpatient department of two hospitals: Mahagujarat Multispecialty Hospital, Nadiad, India and SARATHI Institute of Diabetes Sciences, Anand, India. The time period of study as whole was of 6 months.

\section{Data collection}

The study got the approval from the Human Resource Ethics Committee, Department of Pharmacology, Pramukhswami Medical College, Karamsad, India, for its operation. Data were collected during the period of $2 \frac{1}{2}$ to 3 months, i.e., from August 2016 to October 2016. Evaluation and analysis of the data were done in remaining 3 months. A total of about 200 patients data, i.e., (hypertension:diabetes) $=(100: 100)$ with age greater than 18 years were reviewed. Their demographic information such as gender, age, and BP were noted from patient's OPD sheet. Along with details, information on prescribed medications, and especially, of FDCs was notified on the basis of their type, content names, and dosage. Information about patient's particular comorbid condition was also being collected.

\section{Statistical evaluation}

After data collection process, separation of data was done in terms of specific therapy kind, i.e., two/three drug therapy, type of FDC, and dose and patient's consumption proportion, respectively. Statistical analysis was performed through usage of Microsoft Excel. Appropriate results obtained here are depicted in tabular form. Concern regarding patient's privacy and confidentiality was maintained during the study and will remain conserved even during the publication.

\section{RESULTS}

Here, the demographic details entered were indicative of male and female proportion suffering from hypertension and diabetes. The ratio for the same was 48:52 for hypertensives and 60:40 for diabetics. The proportion of comorbidity present in hypertensive patients was $61 \%$, and in diabetic patients, it was $72 \%$. In dependence of patient's health condition, he/she is being started with particular two-/threedrug therapy. In case of hypertensive patients, the utilization of twodrug therapy is about $97 \%$ with no three drug treatment. Whereas, in diabetics, two-drug therapy counts $76 \%$ and three-drug therapy counts $15 \%$ which in total contribute $91 \%$ of combined drug therapy. The most often prescribed combination observed in hypertensives is of CCBs and ARBs contributing 53\%. Similarly, for diabetics, the most common prescribed two-drug combination was of biguanides and sulfonylureas accounting $63 \%$ and three-drug therapy was of metformin, sulfonylureas, and glitazones combination, contributing $11 \%$, respectively.

Table 1 shows age- and gender-wise distribution of the patients suffering from hypertension and diabetes. It shows that the numbers of hypertensive patients are seen more in the elderly group. Whereas, age group between 51 and 60 years suffered more from diabetes compared to other age groups. There is not much difference in gender distribution for both morbidities.

Table 2 shows comorbid conditions of the patients of different age groups. It shows most of the patients suffered from single morbidity. Patients having hypertension with other comorbidities are very less, i.e., one patient in the age group of 51-60. Patients of diabetes with maximum comorbidities are seen in the elderly patients, i.e., 3 comorbidities.

Table 3 shows age-wise distribution of patients on basis of number of antihypertensive and antidiabetic drugs per prescription. In hypertensive patients, two drug treatments are found to be maximum in elderly group and are seen lowest in 31-40 years age group. In diabetic patients, two-drug therapies are found maximum in 51-60 years age group and lowest in 18-30 years. More than three antidiabetic drugs are seen prescribed in the age group of 51-60 years (Table 4).

\section{DISCUSSION}

A prescription-based survey is significant in terms of measuring/ evaluating the ethos of doctors, i.e., physicians and also the customs of chemists/druggists in case of distributing medications [8] so as to achieve rationality in maintaining proper medical protection [9]. The other important matters which are to be considered are looking after the WHO as well as the JNC regulations to maintain sanity of medications as per the essential drugs list [10].

The study carried out here disclosed that the hypertension is seen to be more prevailing in females (52\%) compared to males (48\%) which is identical to the project conducted by Bajaj et al. (2012) in Northern

Table 1: Demographic detail

\begin{tabular}{|c|c|c|c|c|c|c|}
\hline \multirow[t]{2}{*}{ Age (years) } & \multicolumn{3}{|c|}{ Hypertensives, n (\%) } & \multicolumn{3}{|c|}{ Diabetics, n (\%) } \\
\hline & Male & Female & Total & Male & Female & Total \\
\hline $18-30$ & 0 & 0 & 0 & $4(4)$ & $6(6)$ & $10(10)$ \\
\hline $31-40$ & $6(6)$ & $3(3)$ & $9(9)$ & $8(8)$ & 0 & $8(8)$ \\
\hline $41-50$ & $6(6)$ & $4(4)$ & $10(10)$ & $11(11)$ & $6(6)$ & 17 (17) \\
\hline $51-60$ & $10(10)$ & 17 (17) & 27 (27) & $20(20)$ & $18(18)$ & $38(38)$ \\
\hline$>60$ & $26(26)$ & $28(28)$ & $54(54)$ & 17 (17) & $10(10)$ & 27 (27) \\
\hline Total & $48(48)$ & $52(52)$ & $100(100)$ & $60(60)$ & $40(40)$ & $100(100)$ \\
\hline
\end{tabular}

Table 2: Co-morbid conditions

\begin{tabular}{|c|c|c|c|c|c|c|c|c|c|c|}
\hline \multirow[t]{3}{*}{ Age group (years) } & \multicolumn{5}{|c|}{ Hypertensives } & \multicolumn{5}{|c|}{ Diabetics } \\
\hline & \multicolumn{10}{|c|}{ Number of comorbidities, n (\%) } \\
\hline & 1 & 2 & 3 & 4 & Total & 1 & 2 & 3 & 4 & Total \\
\hline $18-30$ & 0 & 0 & 0 & 0 & 0 & 0 & 0 & 0 & 0 & 0 \\
\hline $31-40$ & $1(1)$ & $2(2)$ & 0 & 0 & $3(3)$ & $1(1)$ & 0 & $2(2)$ & 0 & $3(3)$ \\
\hline $41-50$ & 7 (7) & 0 & 0 & 0 & 7 (7) & $5(5)$ & $3(3)$ & $2(2)$ & 0 & $10(10)$ \\
\hline $51-60$ & $8(8)$ & $6(6)$ & $2(2)$ & $1(1)$ & 17 (17) & $21(21)$ & $8(8)$ & $6(6)$ & $1(1)$ & $36(36)$ \\
\hline$>60$ & $23(23)$ & $8(8)$ & $3(3)$ & 0 & $34(34)$ & $8(8)$ & $9(9)$ & 3 (3) & 3 (3) & $23(23)$ \\
\hline Total & $39(39)$ & $16(16)$ & $5(5)$ & $1(1)$ & $61(61)$ & $35(35)$ & $20(20)$ & $13(13)$ & $4(4)$ & $72(72)$ \\
\hline
\end{tabular}


India as that showed data of females as $58 \%$ and males accounting $42 \%$ [11], whereas the study ran by Jhaj et al. was exactly opposite, i.e., male sufferers were more than females [12], and also hypertension cases in these studies were seen to be more prevailing in elderly group patients which were similar to a prospective study been carried out at Annamalai Nagar, India [13].

Combinative therapy given in case of, especially, hypertensive patients is helpful in reducing the death rates which occurs due to cardiovascular disorders as a chronic comorbid disease with hypertension [14]. As per the JNC-8 report after evaluation, it was revealed that in case of the usage of ARB in management of HTN as a single therapy or in combination therapy with other drugs shows maximum compliance as per its rules and regulations (JNC-8).

Furthermore, the diuretics are found to be used in less amount in case of combination therapy, and here in these experiments, the maximum usage found of combination therapy is of ARBs and CCBs, i.e., most frequently used one which is about $53 \%$ then followed by ARBs and thiazide diuretics (TDs) showing $18 \%$ of the use. Diuretics if used then it is seen more in single-drug therapy and specifically during initiation of hypertension in patient. The least used combination is of BBs and TDs counting only $1 \%$.
The peculiarity of combination is also dependent on extent of the disease also the comorbidity associated with it. For example, combination of BBs and CCBs is used more in condition of arterial hypertension [15]. Usage of diuretics is in such a manner that it is mostly used at low doses even in combination treatment because of it contradictory effects on processes such as glucose balance and also the fat profile [16].

As per the previous studies, the requisite to be considered important is that the drugs/antihypertensives which are used that must possess a coactive/collaborative action even at lower doses and that too with no side effects [17].

DM is chronic disease which comprehends several other metabolic deformities out of that the main one is hyperglycemia [18].

This type of studies on prescription monitoring and estimation can prove as helpful in promoting well-advised drug therapy because of which the assumed level of glucose can be attained in patients and possibilities of death as well as morbidities can be eventually reduced [2]

From this study, we observed that the disease is seen to be more existed among individuals of age group 50-60 years, i.e., about 38\%.

Table 3: Prescribing pattern

\begin{tabular}{|c|c|c|c|c|c|c|}
\hline \multirow[t]{2}{*}{ Age group (years) } & \multicolumn{3}{|c|}{ Hypertensives, n (\%) } & \multicolumn{3}{|l|}{ Diabetics, n (\%) } \\
\hline & Two-drug therapy & Three-drug therapy & Total & Two-drug therapy & Three-drug therapy & Total \\
\hline $18-30$ & 0 & 0 & 0 & $3(3)$ & 0 & $3(3)$ \\
\hline $31-40$ & $8(8)$ & 0 & $8(8)$ & $5(5)$ & $2(2)$ & 7 (7) \\
\hline $41-50$ & $18(18)$ & 0 & $18(18)$ & $17(17)$ & $3(3)$ & $20(20)$ \\
\hline $51-60$ & $25(25)$ & 0 & $25(25)$ & $29(29)$ & 7 (7) & $36(36)$ \\
\hline$>60$ & $46(46)$ & 0 & $46(46)$ & $22(22)$ & $3(3)$ & $25(25)$ \\
\hline Total & 97 (97) & 0 & $97(97)$ & 76 (76) & $15(15)$ & $91(91)$ \\
\hline
\end{tabular}

Based on number of drugs in single FDCs. FDCs: Fixed dose combinations

Table 4: Frequencies of specifically prescribed FDCs

\begin{tabular}{|c|c|c|c|c|c|c|c|}
\hline \multirow[t]{2}{*}{ Age group (years) } & \multicolumn{7}{|c|}{ Hypertensives (two-drug therapy), n (\%) } \\
\hline & $\mathrm{ARB}+\mathrm{CCB}$ & $\mathrm{BB}+\mathrm{CCB}$ & $\mathrm{BB}+\mathrm{ARB}$ & ARB+TD & TD+CA & KD+LD & Total \\
\hline $18-30$ & 0 & 0 & 0 & 0 & 0 & 0 & 0 \\
\hline $31-40$ & $4(4)$ & $3(3)$ & 0 & $1(1)$ & 0 & 0 & $8(8)$ \\
\hline $41-50$ & $4(4)$ & $2(2)$ & 0 & $2(2)$ & $1(1)$ & $1(1)$ & $10(10)$ \\
\hline $51-60$ & $7(7)$ & $4(4)$ & $2(2)$ & $6(6)$ & 0 & $3(3)$ & $22(22)$ \\
\hline$>60$ & $38(38)$ & $8(8)$ & 0 & $9(9)$ & 0 & $2(2)$ & $57(57)$ \\
\hline \multirow[t]{3}{*}{ Total } & $53(53)$ & $17(17)$ & $2(2)$ & $18(18)$ & $1(1)$ & $6(6)$ & $97(97)$ \\
\hline & \multicolumn{7}{|c|}{ Diabetics (two-drug therapy), n (\%) } \\
\hline & $\mathrm{B}+\mathrm{SU}$ & $\mathrm{B}+\mathrm{G}$ & B+AGI & B+DPP & B+CYNOCOBAL & SU+G & Total \\
\hline $18-30$ & $3(3)$ & 0 & 0 & 0 & 0 & 0 & $3(3)$ \\
\hline $31-40$ & $3(3)$ & $1(1)$ & 0 & 0 & 0 & $1(1)$ & $5(5)$ \\
\hline $41-50$ & $12(12)$ & 0 & 0 & $1(1)$ & $1(1)$ & 0 & $14(14)$ \\
\hline $51-60$ & $28(28)$ & $2(2)$ & $1(1)$ & $1(1)$ & $2(2)$ & 0 & $34(34)$ \\
\hline$>60$ & $17(17)$ & 0 & $1(1)$ & $1(1)$ & $1(1)$ & 0 & $20(20)$ \\
\hline Total & $63(63)$ & $3(3)$ & $2(2)$ & $3(3)$ & $4(4)$ & $1(1)$ & $76(76)$ \\
\hline \multicolumn{8}{|c|}{ Three-drug therapy, n (\%) } \\
\hline & $\mathrm{B}+\mathrm{SU}+\mathrm{G}$ & $\mathrm{B}+\mathrm{SU}+\mathrm{AGI}$ & $\mathrm{B}+\mathrm{AGI+G}$ & Total & & & \\
\hline $18-30$ & 0 & 0 & 0 & 0 & & & \\
\hline $31-40$ & $2(2)$ & 0 & 0 & $2(2)$ & & & \\
\hline $41-50$ & $1(1)$ & $1(1)$ & $1(1)$ & $3(3)$ & & & \\
\hline $51-60$ & $6(6)$ & $1(1)$ & 0 & $7(7)$ & & & \\
\hline$>60$ & $2(2)$ & 0 & $1(1)$ & $3(3)$ & & & \\
\hline Total & $11(11)$ & $2(2)$ & $2(2)$ & $15(15)$ & & & \\
\hline Summed & & & & & & & $91(91)$ \\
\hline
\end{tabular}

ARB: Angiotensin receptor blocker, CCB: Calcium channel blocker, TD: Thiazide diuretics, CA: Centrally acting agents, KD: Potassium-sparing diuretics, LD: Loop diuretics, B: Biguanides, SU: Sulfonylureas, G: Glitazones, Alpha-glucosidase inhibitors, DPP: Dipeptidyl peptidase inhibitor, CYANOCOBAL: Cyanocobalamin, FDCs: Fixed dose combinations 
Table 5: Prescribing pattern of frequently prescribed FDCs

\begin{tabular}{|c|c|c|c|c|c|c|c|}
\hline \multicolumn{8}{|c|}{ Hypertensives (ARBS+CCBS), n (\%) } \\
\hline Age group (years) & \multicolumn{2}{|l|}{$\mathrm{T}+\mathrm{A}(40 / 5) \mathrm{mg}$} & \multicolumn{2}{|l|}{$\mathrm{T}+\mathrm{C}(40 / 10) \mathrm{mg}$} & \multicolumn{2}{|c|}{$0+A(40 / 10) \mathrm{mg}$} & Total \\
\hline $18-30$ & \multicolumn{2}{|l|}{0} & \multicolumn{2}{|l|}{0} & \multicolumn{2}{|l|}{0} & 0 \\
\hline $31-40$ & \multicolumn{2}{|l|}{$4(4)$} & \multicolumn{2}{|l|}{0} & \multicolumn{2}{|l|}{0} & $4(4)$ \\
\hline $41-50$ & \multicolumn{2}{|l|}{$4(4)$} & \multicolumn{2}{|l|}{0} & \multicolumn{2}{|l|}{0} & $4(4)$ \\
\hline $51-60$ & \multirow{2}{*}{\multicolumn{2}{|c|}{$8(8)$}} & \multicolumn{2}{|l|}{$1(1)$} & \multirow{2}{*}{\multicolumn{2}{|c|}{$\begin{array}{l}0 \\
1(1)\end{array}$}} & $9(9)$ \\
\hline$>60$ & & & $12(12)$ & & & & $36(36)$ \\
\hline Total & \multicolumn{2}{|l|}{$39(39)$} & \multicolumn{2}{|l|}{$13(13)$} & \multicolumn{2}{|l|}{$1(1)$} & $53(53)$ \\
\hline \multicolumn{8}{|c|}{ Diabetics (B+SUS) and (B+SUS+Glitazones), n (\%) } \\
\hline & $\begin{array}{l}\text { M+Glim. } \\
(0.5 / 500) \mathrm{mg}\end{array}$ & $\begin{array}{l}\text { M+Glyc. } \\
\text { (50/500) mg }\end{array}$ & $\begin{array}{l}\text { M+Glipi. } \\
\text { (80/500) mg }\end{array}$ & $\begin{array}{l}\text { M+Glyb. } \\
(1.25 / 500) \mathrm{mg}\end{array}$ & $\begin{array}{l}\text { M+Gliben. } \\
(1 / 500) \mathrm{mg}\end{array}$ & $\begin{array}{l}\text { M+Glim.+Piog. } \\
(2 / 500 / 15) \mathrm{mg}\end{array}$ & Total \\
\hline $18-30$ & 0 & $1(1)$ & $2(2)$ & 0 & 0 & 0 & $3(3)$ \\
\hline $31-40$ & 0 & $2(2)$ & 1 (1) & 0 & 0 & $2(2)$ & $5(5)$ \\
\hline $41-50$ & $5(5)$ & 0 & $6(6)$ & 0 & $1(1)$ & 1 (1) & $13(13)$ \\
\hline $51-60$ & $14(14)$ & $8(8)$ & 5 (5) & 0 & 0 & $6(6)$ & 33 (33) \\
\hline$>60$ & $6(6)$ & $3(3)$ & $8(8)$ & 1 (1) & 0 & $2(2)$ & $20(20)$ \\
\hline Total & $25(25)$ & $14(14)$ & $22(22)$ & 1 (1) & $1(1)$ & 11 (11) & $74(74)$ \\
\hline
\end{tabular}

Based on dose of each drug. T: Telmisartan, A: Amlodipine, C: Clinidipine, O: Olmesartan, M: Metformin, Glim: Glimepiride, Glyc: Glyclazide, Glipi: Glipizide,

Glyb: Glyburide, Gliben: Glibenclamide, Piog: Pioglitazone, ARB: Angiotensin receptor blocker, CCB: Calcium channel blocker

This detection is found similar to a research work been conducted by Upadhyay et al. [19] as conventionally too it was observed among people of age $>50$ years. It is observed that males are suffering more than females which is opposite to the study been conducted in New York [20].

Around 91\% of patients are receiving combination therapy such as DM is a slowly spreading chronic metabolic disease that cannot be controlled by single-drug therapy, which was similar to a study conducted once where the ratio of patients receiving combination therapy was more than $71.5 \%$. The most often prescribed ones contain biguanides+sulfonylureas accounting $63 \%$ which was similar to a study conducted in the UK portrayed that this mixture showed up better result in terms of level of HbA1C [21]. Then, this was followed with combination of biguanides+thiazolidinedione which counted $3 \%$, and the least prescribed combination was of sulfonylureas+thiazolidinedione, i.e., $1 \%$. In three-drug therapy consideration, the frequently prescribed one was biguanides+sulfonylureas+thiazolidinedione combination which was $11 \%$. This report matched with the one which was once conducted on ambulatory patients in Lahore, Pakistan [22], and also the specific combination of metformin+glibenclamide+pioglitazone contributed $11 \%$ among patients of these studies which was exactly opposite to a study implemented on non-hospitalized patients of Iran [7].

In all the prescribed medication, it has been observed that along with this present study too biguanides are recommended in higher proportion, whether this is in terms of single therapy or combinative therapy, this was applicable for both the treatments [22].

In addition, issuing comorbid conditions and multiple drug therapy, chances of drug interactions, unacceptability, and side effects will be seen aggravating more. For this proper and complete drug, optimization is mandatory by the doctors along with making them aware with the risks. For example, patient with hypertension and diabetes if is given with combinative therapy of BB+ACEI for hypertension specifically, then it will indirectly reduce action of oral hypoglycemic agents either or will result into hypoglycemia in the patient. This is indicative that appropriate dose adjustment is must.

Lifestyle changes, diet monitoring, regular exercises, and weight loss can be considered as important ways in controlling DM and several other severe diseases [23].

Eventually, prescribing practices must be developed on the basis of scientific proofs and considering drug management guidelines and regulations as standard in terms of adjusting proper dosage regimen depending on condition of the particular patient [22].

\section{CONCLUSION}

The prescribing methodology of FDCs is found to be more in common here than single drug therapy. The most often prescribed FDC for hypertension found is of ARBs and CCBs group kind. Similarly, for diabetes, the frequently prescribed combination was of biguanides and sulfonylureas. Maximum medications belonged to these two classes. Positive results in the end were seen in case of BP and glucose levels because of these prescribed medications. More awareness is still required among patients regarding the importance of regular uptake of medications.

\section{ACKNOWLEDGMENT}

The authors would like to thank Mr. Anup Desai and Dr. Vikram Valand of Maha Gujarat Multispecialty Hospital, Nadiad and also Dr. Chintan Vyas of SARTHI Institute of Diabetes Sciences, Anand, for permitting us to perform our desired work and also for their support and cooperation.

\section{REFERENCES}

1. James PA, Oparil S, Carter BL, Cushman WC, Dennison-Himmelfarb $\mathrm{C}$, Handler J, et al. Evidence-based guideline for the management of high blood pressure in adults report from the panel members appointed to the eighth joint national committee (JNC 8). JAMA. Doi: 10.1001/ jama.2013.284427.

2. Ramachandran G, Rohith V, Topno I. Evaluation of prescribing pattern of anti-diabetic drugs using WHO prescribing indicators in a tertiary care hospital in Pondicherry: A cross-sectional study. Int J Clin Pharmacol Thyer 2015;4(5):76-80.

3. Shahir AQ, Kauser S, Dharmendra G, Ahmad AN. Prescribing patterns of anti-diabetic medications in tertiary care teaching hospital, Bareilly, UP, India. J Pharm Sci Innov 2013;2(1):41-6.

4. Sridevi SA, Ganesh M. Study on the Prescription Pattern of Oral Hypoglycemic Agents in Type 2 Diabetes Mellitus in the Outpatient Department of a Tertiary Care Hospital in Chennai. Vol. 6. March; 2016

5. Murthy S, Jambulingappa KL, Gokul, Ramakrishna S, Acharya A, Adake P. Prescribing patterns of anti-hypertensive combinations in a tertiary care setting, Karnataka, India. Drug Invent Today 2011;3(11):265-9.

6. Kale A, Maniyar YA. Prescribing patterns of antihypertensive drugs in a tertiary care hospital, Karnataka, India. Acd J Pharm 2013;2(5):416-8.

7. Moradi M, Mousavi S. Drug use evaluation of diabetes mellitus in nonhospitalized patients. Int J Pharm Pharm Sci 2016;8(8):337-41. 
8. Yuen YH, Chang S, Chong CK, Lee SC, Critchlev JA, Chan JC. Drug utilization in a hospital general medical outpatient clinic with particular reference to antihypertensive and ant diabetic drugs. J Clin Pharm Ther 1998;23:287-94.

9. Suheela SH, Narendranth S, Somashekhar HS, Reshma SR, Keerthi SJ, Ramachandra K. Prescriptive pattern of antihypertensive in a tertiary care hospital using DU-90\%. Int J Pharm Res Dev 2011;4(1):107-13.

10. Sikidar P, Chakravarty P, Purkayastha A, Tigga R. A Study on prescribing pattern of antihypertensive in adult patients attending in a tertiary care hospital of Assam, India. Int J Basic Clin Pharmacol 2016;5(3):975-8

11. Bajaj JK, Sood M, Singh SJ, Jerath P. Prescription patterns of antihypertensive drugs and adherence to JNC VII guidelines in a tertiary care hospital in North India. Int J Med Clin Res 2012;3(2):118-20.

12. Jhaj R, Goel NK, Gautam CS, Hota D, Sangeeta B, Sood A, et al. Prescribing patterns and cost of antihypertensive drugs in an internal medicine clinic. Indian Heart J 2001;53(3):323-7.

13. Nachiya RA, Parimalakrishnan S, Rao MR. Cost analysis of antihypertensive agents in rural population: A prospective study. Int $\mathrm{J}$ Pharm Pharm Sci 2016;8(3):225-30.

14. Mancia G, Grassi G. Antihypertensive treatment: Past, present and future. J Hypertens Suppl 1998;16(1):S1-7.

15. Carré A. Pharmacologic importance of the combination atenolol/ nifedipine in hypertensive patients. Drugs 1998;56 Suppl 2:23-30.
16. Prisant LM, Beall SP, Nicholads GE, Feldman EB, Carr AA, Feldman DS, et al. Biochemical, endocrine, and mineral effects of indapamide in black women. J Clin Pharmacol 1990;30:121-6.

17. Tiwari H, Kumar A, Kulkarni SK. Prescription monitoring of antihypertensive drug utilisation at the Panjab university health centre in India. Singapore Med J 2004;45(3):117-20.

18. Rajan SK, Sivakumar R, Arunaprakash J. The study of plasma glycosylated hemoglobin and fibrinogen levels in patients with Type 2 diabetes mellitus and its complication. Asian J Diabetol 2005;7:9-12.

19. Upadhyay DK, Palaian S, Shanker PR, Mishra P, Sah AK. Prescribing pattern in diabetic outpatients in a tertiary care teaching hospital in Nepal. J Clin Diagn Res 2007;3:248-55.

20. Flier JS, Maratos-Flier E. Obesity. In: Kasper DL, Braunwald E, Fauci AS, Hauser SL, Longo DL, Jameson JL, editors. Harrison's Principles of Internal Medicine. 16 ${ }^{\text {th }}$ ed., Vol. 1. New York: Medical Publishing Division, McGraw-Hill; 2005. p. 422-9.

21. UKPDS 28: A randomized trial of efficacy of early addition of metformin in sulfonylurea-treated Type 2 diabetes. U.K. Prospective diabetes study group. Diabetes Care 1998;21(1):87-92.

22. Bukhsh A, Liaqat I, Javaid S, Bashir M, Khan B, Yaseen H, et al. Prescription analysis of ambulatory patients of diabetes mellitus in Lahore Pakistan. Adv Pharm Ethnopharmacol Med 2014;2(2):21-5.

23. Laakso M, Letho S. Epidemiology of macrovascular disease in diabetes. Diabet Rev 1997;5:294-315. 